\title{
Arqueología del
}

País Valenciano:

panorama y perspectivas

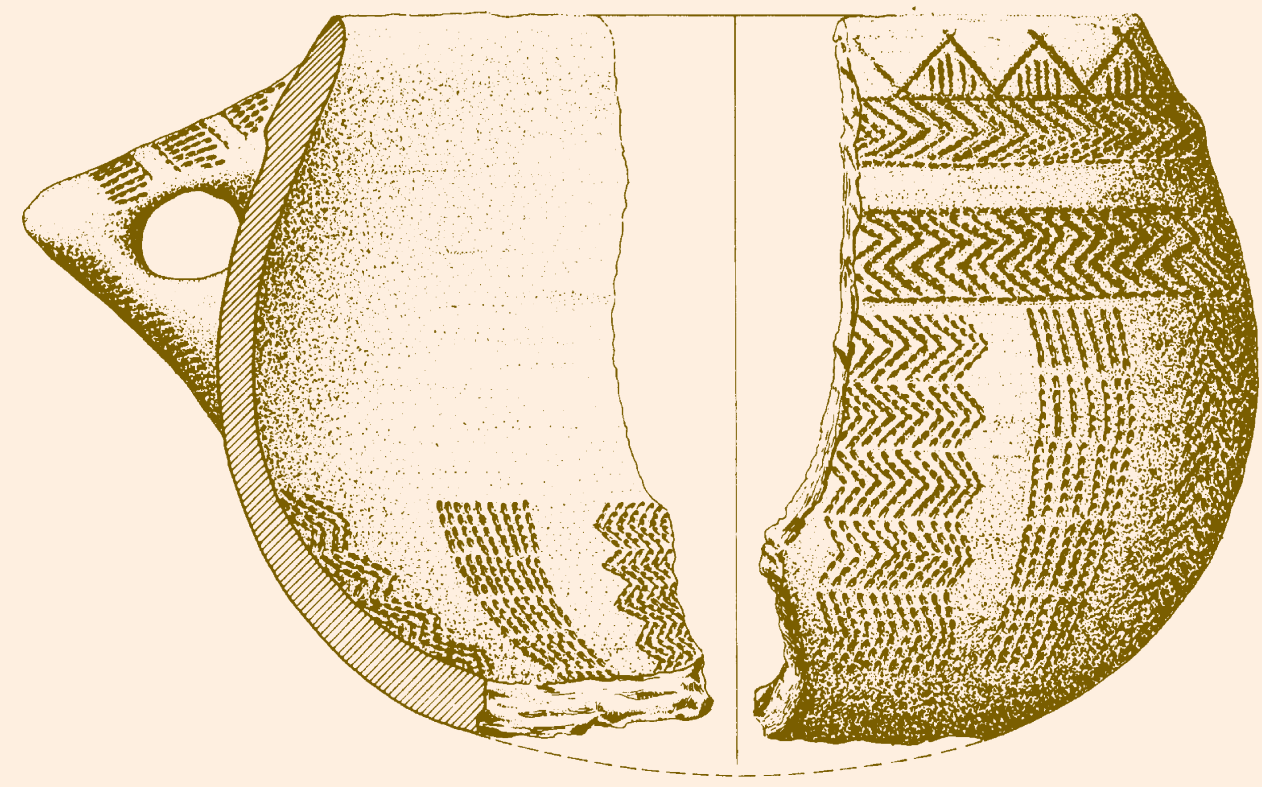

$$
\text { 造 }
$$

Anejo de la revista Lvcentvm

Universidad de Alicante 
Este libro ha contado para su edición con la ayuda de la Consellería de Cultura de la Generalitat Valenciana y de la Diputación Provincial de Alicante.

Edita:

Secretariado de Publicaciones Universidad de Alicante

Portada:

Enrique (Gabinete de Prensa. Universidad de Alicante)

Imprime:

Gráficas Ciudad, S.A. - Alcoy

ISBN: 84-600-3906-4

Depósito Legal: A-317-1985

Reservados todos los derechos. No se permite reproducir, almacenar en sistemas de recuperación de la información ni transmitir alguna parte de esta publicación, cualquiera que sea el medio empleado -electrónico, mecánico, fotocopia, grabación, etc.-, sin el permiso previo de los titulares de los derechos de la propiedad intelectual.

Estos créditos pertenecen a la edición impresa de la obra.

Edición electrónica:

E Espagrafic 


\section{ARQUEOLOGÍA DEL PAÍS VALENCIANO:}

Panorama y perspectivas

Rafael Arroyo llera

Fuentes numismáticas:

B. La moneda imperial romana 


\section{Índice}

\section{Portada}

\section{Créditos}

\section{Fuentes numismáticas}

B. La moneda imperial romana

Rafael Arroyo Ilera.................................................. 5

1. Planteamiento histórico de la moneda imperial romana

2. Los problemas de la numismática romana imperial

2. Líneas actuales de investigación

3. Directrices para el futuro ................................. 33

Bibliografía .................................................... 35 


\section{Fuentes numismáticas:}

B. La moneda imperial romana

1. Planteamiento histórico de la moneda imperial romana

rente a los estudios que se han venido haciendo en la Península sobre la moneda ibérica e hispánica, la moneda romana no tiene una atención concreta hasta tiempos relativamente modernos. Mientras existan cecas en Hispania sus emisiones han interesado a los investigadores, pero en el momento que la moneda es importada desde talleres extrapeninsulares se la ha considerado como elemento extraño. Por ello si tenemos que hacer una referencia histórica no tenemos más remedio que referirnos a autores no españoles, los cuales estudiaron la moneda romana de forma general, pero sin precisar dato alguno sobre Hispania. 


\section{Arqueología del País Valenciano: panorama y perspectivas}

El primer análisis referido al período imperial posiblemente sea el de el Sabatier que hacia 1850 analizarán la producción de oro, plata y cobre de los distintos talleres del Imperio Romano. Aunque la obra más conocida y divulgada hasta el punto que todavía hay publicaciones que la utilizan como referencia es la de $\mathrm{H}$. Cohen (1880), el cual hacia 1859 publicó en ocho volúmenes su descripción de la moneda acuñada por el Imperio Romano. Por esas mismas fechas L. Müller (1860) terminaría su obra sobre la numismática de la antigua África, que aunque una gran parte no son análisis de la moneda romana trae referencias que para la fecha de publicación son muy aptas todavía.

A comienzos del siglo E. Babelon (1901-1904) publicó una obra, que continúa realizándose reimpresiones, sobre la moneda griega y romana. Pero todas ellas son obras que se hallan dentro de un contexto de investigación antigua. Este panorama cambiará con la publicación de la obra de J. Maurice en 1908 sobre la numismática constantiniana. Estudio que por primera vez se enfrenta con el problemático análisis de las monedas acuñadas en los siglos IV y V d.C. Su propia estructura suponía un cambio, pues el tratamiento de ver la evolución de la moneda tomando como referencia las cecas 


\section{Rafael Arroyo llera \\ Fuentes numismáticas}

y los talleres, es un sistema que en la actualidad todavía se sigue.

Hacia 1923 se inicia la colección de moneda romana imperial más importante que existe, se trata de la Roman Imperial Coinage. Cuyo primer volumen dedicado desde Augusto y Vitelio fue obra de H. Mattingly y E. Sydenham, (1923). Tres años más tarde en 1926 los mismos autores publican el volumen II comprendiendo el período que va desde Vespasiano a Adriano. El proyecto de tener una obra moderna sobre la problemática de la moneda imperial romana se iba poco a poco realizándose gracias al trabajo de ambos autores, pues en 1930 sacarán el tercer volumen, en esta ocasión dedicado a Antonino Pío, Marco Aurelio y Commodo.

Lo que con el tiempo sería el IV volumen ocuparía tres partes y se publicaría en tres fechas, hacia 1936 se estudió el reinado desde Pertinax a Geta. En 1938 se unió al equipo de investigación C.V. Sutherland publicando el período desde Macrino a Pupenio. Y en 1949 dieron por terminado este período al sacar desde Gordiano III a Uranio Antonino.

La obra iniciada el 1923 era de una ambición superior a la labor que podían dar sus editores, por ello se debió de encargar algunos volúmenes a especialistas. En este sentido el si- 


\section{Arqueología del País Valenciano: panorama y perspectivas}

glo III, el período que abarca desde Valeriano a Floriano se lo encargaron a P. Webb (1927), que era una autoridad en la materia, sobre todo después de la Publicación de su The reign and coinage of Carausius y del The coinage of Allectus. P. Webb publicó el volumen $\mathrm{V}$ en dos partes que sucesivamente fueron dadas a conocer en 1927 y 1933 fecha que terminó con el reinado de Allectus.

Por estas fechas la responsabilidad de la publicación del RIC, como generalmente se conoce esta colección, estaba en manos de Mattingly, Sutherland y Carson, los cuales lo mismo que se había hecho con Webb encargaron el período último o sea el de Valentiniano a Teodosio a Pearce, obra que fue terminada en 1933.

Con la publicación del volumen IX en 1933 se abre un paréntesis en la continuación de la obra que pudo cambiar el proyecto inicial. Pero al fin se pudo continuar, al publicarse en 1966 el tomo VII obra de P. Bruun sobre el período desde Constantino a Licinio, en estos años la responsabilidad recaía en Sutherland y Carson al ir desapareciendo los iniciadores.

Siete años más tarde en 1973 el mismo Sutherland publicaría un período extremadamente complejo el de Diocleciano a 


\section{Rafael Arroyo llera \\ Fuentes numismáticas}

Maximino sacando el que sería el volumen VI. Por tanto solo quedaba investigar el período de la familia de Constantino. Etapa de unas dificultades tremendas por la abundancia de material, talleres y cecas, pero esto fue resuelto por uno de los especialistas actuales más conocidos, el Conservador Jefe del Gabinete de Monedas y Medallas del British Museum, J.P.C. Kent que en 1981 publicó el período desde el 337 al 364 d.C., incorporando todo el aparato bibliográfico hasta ahora conocido sobre esta etapa.

Al lado de esta colección que indudablemente supone un avance importante en la numismática imperial se publicaron algunos volúmenes dedicados a los fondos materiales del Gabinete de Monedas y Medallas del British Museum (MATTINGLY, 1923, 1950). Hasta ahora solamente conocidos 6 volúmenes terminando con Pupenio.

Un intento también importante en la creación de un Corpus de moneda romana es la de Banti-Simoneti autores del Corpus Nummorum Romanorum. Obra extremadamente pormenorizada pues llevan 18 volúmenes y hasta ahora han terminado con el reinado de Nerón (nota 1).

En 1964 se constituyó en Wetteren (Bélgica) la Sociètè d'Edition Numismatique Romaine, que inicialmente había re- 


\section{Arqueología del País Valenciano: panorama y perspectivas}

cibido el nombre de Numismatique Romaine, Essais, Recherces et Documents y fue una sociedad creada para la difusión de las obras consagradas a la moneda romana. Hasta la actualidad Ilevan publicados XIII volúmenes, por lo general agrupados en tres temas: estudio de las acuñaciones de un emperador: P. Bastien (1964), Le monnayage de Magnence, y Le monnayage de bronze de Postume (1967). Al lado están las publicaciones de tesoros, como el de Canakkale (Turquía), Saint-Mard I, Lignieres y Osmery, Arras. Y lugar destacado es la publicación de las investigaciones sobre la moneda acuñada por el taller de Lyon desde 274 d.C., por ahora en cuatro volúmenes.

Al lado de estas obras que de alguna manera están dentro de una colección podemos señalar los innumerables estudios publicados en revistas como Revue Numismatic, Numismatic Chronicle, Nummus, Acta Numismática y Quaderni Ticinesi en las cuales se han ido recogiendo todas las investigaciones más recientes de Callu, Bastien, Kent, Depeyrot, Bost.

\section{Los problemas de la numismática romana imperial}

La numismática romana imperial que se inicia en Hispania a partir del cierre de las cecas locales presenta tres grupos de 


\section{Rafael Arroyo llera \\ Fuentes numismáticas}

problemas: problemas de circulación monetaria, del material numismático y de descripción de ese material. Siguiendo este orden expondremos su situación actual.

\section{a) Problemas de la circulación monetaria}

A partir del cierre de las cecas locales Hispania pasará a depender totalmente de una política monetaria dirigida desde la Metrópoli. La moneda no estará en relación con el ejército, sino con el comercio, con las necesidades de la economía. Por ello los problemas que la numismática imperial presenta en la Península desde el siglo I al siglo V d.C., van unidos a las oscilaciones de la Metrópoli, resulta casi imposible conocer la problemática del País Valenciano desde estas tierras, sin profundizar en la política que Roma tendrá en cada momento.

Bajo los últimos años de la dinastía Claudia, concretamente con Claudio, Roma cerró todas las cecas provinciales del Oeste del Imperio, quedando sólo Roma como ceca senatorial o sea la única que podía acuñar moneda de bronce. Este hecho y el que Roma permaneciera inactiva durante una gran parte del reinado provocó una falta de moneda que dio lugar a monedas realizadas localmente imitando los tipos oficiales de Roma. Este tipo de imitaciones sigue siendo un problema dentro de la circulación de este período. 


\section{Arqueología del País Valenciano: panorama y perspectivas}

En principio no se sabe quién acuñó dichas imitaciones. Sutherland (1935) que estudió este aspecto en Britania al darse cuenta que gran parte de dichas monedas aparecían cerca de los campamentos militares pensó que debieron de ser acuñados por el ejército, para el pago de las tropas. Por su parte L. Laffranchi (1949) creyó que esto fue producto de falsificadores hábiles o el producto de una ceca instalada en un campamento militar. J.B. Giard (1970, 39-40) que analizó esta cuestión en el contexto galo añadió a esta hipótesis la posibilidad de que se tratara de simples particulares, cambistas, o financieros reconocidos por el propio emperador. Para J.B. Giard el Senado en este momento perdió el control de la emisión de monedas de bronce, control que fue absorbido por el emperador quien quizá no sólo autorizó estas acuñaciones sino que las debió de estimular para favorecer el comercio. Por último M. Campo (1974) analizó las características que presentaban dichas imitaciones en los hallazgos peninsulares. El problema es extremadamente complejo, pues en Hispania ya no habían fuerzas militares que hicieran necesarias estas imitaciones y por otro lado el estilo y la técnica de imitación de las monedas aparecidas en la costa mediterránea, Cataluña, País Valenciano, son muy superiores a las realizadas en la Galia y Britania. Por tanto se precisa conocer el volumen y los tipos de estas monedas que se 


\section{Rafael Arroyo llera \\ Fuentes numismáticas}

hallan en los diferentes monetarios de Valencia, Murcia y Albacete, cuantificarlos y relacionarlos con los aparecidos en otras partes de la Península y por último con los de otras partes del Imperio.

El reinado de Nerón desde el punto de vista numismático resulta interesante pues bajo su gobierno se realizará una reforma monetaria que modificará por primera vez los patrones metrológicos establecidos por Augusto. Las motivaciones siguen siendo una incógnita. C.H.V. Sutherland (1974) lo explicó en función del incendio de Roma el cual obligaría para su reconstrucción a una importante cantidad de dinero. Dicha reforma que naturalmente se refleja en las tierras objeto de estudio, parece ser que afectó aprovisionando con emisiones posteriores a la reforma únicamente. No conocemos caso alguno de moneda de Nerón anterior a dicha decisión, es lo que provisionalmente hemos visto en el País Valenciano, desconocemos las circunstancias de Murcia y Albacete.

Por otra parte en caso de entrar en la circulación sólo moneda reformada el problema es saber el motivo de ello.

Todo el período revolucionario posterior a la muerte de Nerón es de gran interés y al mismo tiempo, por la falta de 


\section{Arqueología del País Valenciano: panorama y perspectivas}

estudios, uno de los capítulos más desconocidos. Nunca como en estos momentos la moneda pasa a ocupar uno de los elementos propagandísticos claves y por otro lado se da un hecho nuevo: la apertura del taller de Tarraco. La moneda vuelve a estar en función básicamente del ejército. Desconocemos la cuantificación de las acuñaciones de Galba, Otón y Vitelio. Las emisiones más abundantes. Cuál fue la relación entre los tipos de monedas acuñadas, sestercios, ases y denarios, resultados parciales para Valencia los tenemos, al igual que en Itálica y Conimbriga. Pero todo se halla dentro de un proceso de hipótesis (ARROYO, 1982 b), pues se observan ciertas diferencias en la circulación monetaria. No hay que olvidar por otra parte que se trata de monedas emitidas en un breve período 68-69 d.C., y como reflejo de una soberanía por parte del ente emisor. Este hecho lo diferencia de la moneda que nace para circular por unas necesidades económicas generales.

El período entre el año 69 y el 96 d.C., es el dominado bajo la política de los Flavios. Supone un cambio con toda la trayectoria anterior. Por una parte desde Vespasiano la moneda se acuñará de forma regular y se iniciará la costumbre de fechar a través del método de reflejar el consulado o la tribunicia potestad. Interesa conocer el volumen de las emisio- 


\section{Rafael Arroyo llera \\ Fuentes numismáticas}

nes de Vespasiano, Tito y Domiciano. Las monedas año de cada uno y las diferencias entre los tipos de monedas. Por otra parte es conveniente concretar cuándo comienzan a llegar de forma regular a nuestras tierras las nuevas monedas o sea cuándo se incorporan a la circulación general. Existe un problema al utilizar bibliografía antigua y es la confusión que ha existido al tener que precisar entre un as y un dupondio, pues ambos en una gran parte de los trabajos de algunos años se engloban bajo el término ambiguo e inexacto de mediano bronce. Al parecer bajo esta dinastía la moneda de plata es más abundante y de mejor calidad si las comparamos entre las primeras y las últimas. ¿Fue esto el reflejo de un período de estabilidad económica? La política general de Vespasiano favorable a la Península influyó en un tipo de aprovisionamiento diferente al de las otras provincias del Imperio. Estas pueden ser una serie de cuestiones que este momento plantea, y que únicamente con publicaciones de los hallazgos y de los materiales conservados en los monetarios oficiales podremos de alguna forma contestar.

La dinastía de los Antoninos es quizás uno de los momentos más problemáticos en la circulación monetaria, pero al mismo tiempo más falto de estudios. Nunca como en esta época los datos históricos pueden estar más en relación con los 


\section{Arqueología del País Valenciano: panorama y perspectivas}

propios numismáticos. Nos referimos a ver las conexiones existentes entre el grupo senatorial hispano, que sin duda fue un grupo de presión importante y el desarrollo económico de la Península, con el arrastre que ello comportaba desde un punto de vista monetario (PIGANIOL, 1965).

Bajo Trajano y Adriano se inicia un incremento del sestercio que hemos podido comprobar en las tierras valencianas, pero también es normal en otras partes de la Península. Esto mismo ocurrió con la moneda de plata o sea el denario. Si históricamente está comprobado que bajo la dinastía la exportación del vino, aceite y garum sufrió un incremento importante y que eran elementos no precisamente en manos de terratenientes. Si por otra parte la riqueza estaba bien repartida como se ha podido observar por los datos sobre las liberalidades, entonces cabe pensar que quizá hubo alguna relación entre el aumento observado del sestercio y de la plata y el desarrollo en Roma de este clan hispánico (MANGAS, 1971).

Qué emisiones de sestercios son las más abundantes y cuál es la relación con otros puntos de la Península pueden ser hipótesis de trabajo y de lo cual hoy día no se tienen demasiados datos. 


\section{Rafael Arroyo llera \\ Fuentes numismáticas}

El último período del mandato de los Antoninos coincide con una disminución del numerario y se observa una cierta depreciación. No son hechos aislados dentro del término de circulación monetaria. Nosotros pensamos que debió de haber alguna relación entre: los reclutamientos y la obligación de invertir en Italia, que provocaron una sangría humana y una descapitalización que fue unida a una baja clara en el precio del aceite. Estos planteamientos únicamente con estudios sobre el numerario de este período podrán confirmar si ello es cierto (PANELLA. 1972. CARANDINI, 1969-70).

El siglo III con el que se da entrada al Bajo Imperio Romano es sin duda uno de los períodos más interesantes por la cantidad de novedades y problemas que presenta. Toda la problemática podría centrarse en tres momentos: la primera parte del siglo hasta 253 es la llamada Anarquía Militar, son los años de dominio de los Severos, numismáticamente es un período de prolongación de finales del siglo II. La segunda etapa llegaría hasta el 284, es el momento pleno del llamado crisis del siglo III, innovaciones monetarias, invasiones, inflaciones, depreciación de la moneda. Y finalmente hasta el año 305 que es el intento de reacción para salir de toda la crisis a través de la reforma de Diocleciano. 


\section{Arqueología del País Valenciano: panorama y perspectivas}

En esquema éste es el planteamiento de los problemas de los cuales se sabe muy poco. Se desconoce la política seguida por los Severos en la Península y mucho menos sobre los territorios objeto de este Coloquio. Tenemos tan sólo un dato referente a la introducción del antoniniano en la Península, que fue sin duda de especies tardías, pero no sabemos el motivo.

De la importante inflación que afectó a todo el Imperio en el 266 hemos estudiado su impacto en el País Valenciano (ARROYO, 1982 a), pero hay que obtener datos comparativos con Murcia y Albacete. Por otro lado también en parte hemos analizado y cuantificado las acuñaciones de los llamados emperadores galos-romanos, pero faltan datos de otros lugares con los que se puedan reafirmar las hipótesis o ver las fisuras que puedan tener los planteamientos.

Por último la circulación monetaria bajo la llamada Tetrarquía presenta un triple aspecto: Existen antoninianos con la marca XXI, que indudablemente son monedas realizadas bajo la pauta establecida por la llamada reforma de Aureliano. Existen los "follis" de la reforma de Diocleciano de un tamaño grande $30 \mathrm{~mm}$. Y además existen los llamados "follis-radiados" también producto de la reforma. 


\section{Rafael Arroyo llera \\ Fuentes numismáticas}

Qué significado tuvo la reforma de Diocleciano, cómo se combinaron todas estas piezas dentro de la circulación y a qué niveles se hallaba todavía la inflación monetaria, son cuestiones planteadas y al menos en nuestras tierras ni siquiera iniciado su estudio.

El hecho es que nos encontramos con un siglo III que desde la Numismática es muy complejo pues se trata de un período de transición entre dos mundos monetarios distintos: el del Alto Imperio dominado por el denario y el sestercio y el del Bajo Imperio dominado por la moneda de vellón.

El siglo IV d.C., presenta problemas diferentes a los siglos anteriores dado que la estructura monetaria ha cambiado notablemente. La moneda de vellón se ha generalizado uniformándose los tipos y expansionándose las cecas que se multiplicarán y se repartirán por todas las partes del Imperio. En consecuencia será una etapa de moneda muy abundante, con muchos datos que antes no poseíamos, pero también su pequeño tamaño puede en algunos casos pasar desapercibida.

En la moneda del siglo IV que de alguna manera cabría dividirla en tres períodos: 1) desde el 305 al 337 dominio de Constantino I y su familia. 2) Desde el 337 al 364 o sea la re- 


\section{Arqueología del País Valenciano: panorama y perspectivas}

forma de Constancio II, y 3) desde el 364 al 423 comprendiendo la política de Valentiniano I y terminando con la de Teodosio. Estas divisiones engloban una serie de hechos claves como reformas, cambios, usurpaciones y varias crisis.

Los problemas de esta época son de lo más diverso. Empezando porque no sabemos ni siquiera el nombre de las monedas de vellón. Así hay autores que denominaron a esta moneda "pequeños bronces" que es la forma más ambigua, inexacta y equívoca para llamar a una moneda.

Después y tras largos debates se llamó "follis" y últimamente parece que se acepta la forma "nummus". Mientras tanto como se halla el Gobierno de Magnencio en la Galia y allí se crea el tipo de "maiorina", ello hace que en ocasiones a las acuñaciones romanas se las denomine con este nombre (nota 2).

Si existen problemas en cuanto a la denominación no son nada en comparación con los metrológicos. Hay que tener en cuenta que las reformas metrológicas son normalísimas a lo largo de todo el siglo. Los módulos de las monedas pueden ir desde una talla del 1/48 con un peso de 6,02 gr. al 1/216 con un peso de 1,63 gr. Cada reducción supone una cierta reforma por unos cambios económicos. Por ello encontra- 


\section{Rafael Arroyo llera \\ Fuentes numismáticas}

mos cambios de talla utilizando los mismos reversos, así por ejemplo en el SOL INVICTO COMITI. En otras ocasiones bajo una reducción concreta se crea un nuevo tipo de moneda con otra metrología, en el 330 la talla normal era de 1/132 de la que se pasa en el 336 a la talla del 1/216. Pero dentro de esta normativa se encuentran las acuñaciones de las emperatrices con una talla de $1 / 204$, en consecuencia el llegar a sistematizar toda esta metrología de una forma lógica y dentro de un marco de acontecimientos históricos y económicos es algo que está en gran parte por hacer. Únicamente con la publicación de muchos materiales con los datos correctos de pesos y diámetros puede ayudar a ello (BASTIEN y HUVELIN, 1969).

Otro de los problemas que esta época presenta es la falta de estudio de las cecas y de los talleres emisores. Lo que hasta ahora sabemos por algunas cecas perfectamente estudiadas es que existe una diferencia entre la política monetaria de unas y otras. Ello lleva consigo el que en un mismo momento y bajo los mismos tipos cecas diferentes emitan moneda con diferente metrología.

Cada ceca en este momento se dividirá en diferentes talleres u oficinas. Como cada taller tenía sus propias marcas éstas se multiplicarán, en este sentido no sabemos cómo fun- 


\section{Arqueología del País Valenciano: panorama y perspectivas}

cionaba una ceca, ni el trabajo desarrollado por cada taller, pues todos ellos realizaban los mismos tipos de monedas. ¿Había quizás alguna relación entre las emisiones de un taller y el aprovisionamiento de una zona? En este sentido los problemas son muy complejos y estamos aún muy lejos de una solución (DEPEYROT, 1979).

Si toda esta serie de cuestiones que hemos esbozado las trasladamos al territorio valenciano, murciano y de Albacete nos daremos cuenta que los estudios numismáticos de este período no existen. A lo más que se llega es a la publicación de un tesorillo, siguiendo en todo caso referencias bibliográficas anticuadas.

La situación de nuestra numismática lleva un retraso tal y que podemos señalar como ejemplo el que al referirnos a la moneda del siglo IV y no sabiendo distinguir a qué tipo metrológico nos referimos los englobamos todos bajo el término de $A E-2, A E-4$, según el módulo, cuando a través de los estudios de anglosajones y franceses se sabe que AE-3 pueden acuñarse en diferentes momentos y por tanto afirmar que en la circulación monetaria de un momento abundan los AE-3 es utilizar términos imprecisos. 


\section{Rafael Arroyo llera \\ Fuentes numismáticas}

Si toda la circulación monetaria romana presenta problemas es posible que la de los dos últimos siglos es la más difícil, y a los niveles de los estudios locales la menos atendida.

\section{b) Problemas del material numismático}

En líneas generales es bastante abundante aunque irregular. Por una parte tenemos el material procedente de bibliografía y por otra el de colecciones y Museos.

Los materiales descritos en la Bibliografía son los que contienen más problemas y cuanta más antigüedad tiene la publicación con más razón. Sólo han existido dos intentos serios de plasmar en una publicación hallazgos. Estos fueron los "Hallazgos Monetarios" de F. Mateu Llopis comenzados en la Revista Ampurias, hasta 1952 que siguió publicándose en Numario Hispánico. Al hacer crisis dicha revista los continuó en Numisma en 1971. Durante 35 años el Prof. Mateu ha ido recogiendo noticias de hallazgos de las más diversas épocas. Pero se puede observar una cierta irregularidad en los contenidos, pues cuando el dato aportado es producto de una observación directa del autor entonces es creíble o más exacta, pero en ocasiones eran datos transmitidos, pero no observados directamente, ante lo cual dependía de la formación numismática del comunicante el que dichas piezas 


\section{Arqueología del País Valenciano: panorama y perspectivas}

estuvieran bien clasificadas. De todas las maneras sigue siendo un elenco de noticias de gran utilidad.

El otro intento es el de J. Sánchez Jiménez publicados en 1951 en los Anales del Seminario de Historia y Arqueología de Albacete y continuado en 1962 en Publicaciones del Seminario de Historia y Arqueología de Albacete. Se trata de un inventario de monedas inspeccionadas directamente por el autor y bajo el mismo formato establecido por F. Mateu. La mayoría de los fondos relacionados corresponden al Museo Arqueológico Provincial de Albacete (fondos generales) y colección Sánchez Jiménez.

Al lado de estos repertorios se encuentran artículos diversos que tratan o describen algunas monedas, así tenemos $\mathrm{C}$. Aranegui (1980), sobre el Grau Vell de Saguntum. P.P. Ripollés (1978) y J. V. Cavaller (1980) sobre las excavaciones de San José en Vall d'Uxó. J. M. Doñate Sabastia (1969) sobre arqueología romana de Villarreal. E. Escrig Núñez (1966) sobre numismática Saguntina. C. Giner Bolufer (1947) en la arqueología de Pego y su comarca. El Almanaque de las Provincias de 1902 sobre un hallazgo de monedas de oro. R. Ramos Fernández (1975) sobre las excavaciones de la Alcudia de Elx. P.P. Ripollés (1975) sobre los hallazgos numismáticos en Albocácer, Cabanes y Borriol. M.C. Santandreu 


\section{Rafael Arroyo llera \\ Fuentes numismáticas}

(1961) hallazgos en el cauce del Río Turia. M. Vera Alexandre (1967, 1969, 1972-73, 1975-76 y 1977), diversos hallazgos numismáticos en Sagunto. En todos ellos la parte de numismática es uno más de los materiales descritos, y aunque realizados con la mejor intención no siempre se hallan dentro de la bibliografía más correcta y moderna, como es lógico pues con alguna salvedad se trata de no especialistas en los temas numismáticos.

En cuanto a los materiales de colecciones y Museos, que es la más abundante, se encuentra en un porcentaje altísimo por clasificar. El Museo Arqueológico de Castellón cuenta con una colección de moneda romana imperial interesante, pero no clasificado y menos publicado. Valencia, por su parte cuenta con los fondos del S.I.P. publicados en parte por P.P. Ripollés. El Monetario de la Universidad, totalmente clasificado y a punto de publicarse por nosotros. El Departamento de Arqueología de la Universidad cuenta con fondos propios de los cuales la parte ibérica se halla estudiada, pero no así el conjunto romano. El Museo Municipal del Ayuntamiento, tiene también un monetario teóricamente de monedas aparecidas en el casco urbano, pero no clasificado, aunque en vías de que pronto pase a un grupo de jóvenes conservadores a cuya cabeza se encuentra A. Ribera. En Alicante se halla el 


\section{Arqueología del País Valenciano: panorama y perspectivas}

Museo Arqueológico de la Diputación, con unos fondos importantes, pero la parte romana también sin clasificar. En Murcia se halla el Museo Arqueológico Provincial con fondos inéditos y el de Cartagena también en la misma situación. Y por último el Museo Arqueológico Provincial de Albacete que tiene parte publicada por J. Sánchez Jiménez.

Al lado de estos centros provinciales se hallan pequeños museos locales que en más o menos número cuentan con moneda romana, con el aliciente de que son piezas halladas en la localidad, pero también como los grandes, sin clasificar o publicar. Así tenemos: Museo de Borriana, Gandía, Alcoi y Sagunt. Cuyos materiales en ocasiones al ser utilizados para algún trabajo han sido publicados parcialmente.

En líneas generales el problema de los materiales numismáticos como se comprenderá por lo anterior es la falta de clasificación u ordenación por una parte y de publicación por otra. En ocasiones el monetario consiste en un conjunto de monedas guardadas en cajas de metal sin orden ni concierto. En otra en pequeños sobres con las dificultades que ello supone al tener que consultarlo. La mayoría de estos materiales son de procedencia local, aunque también dicha procedencia se ha perdido muchas veces al intentar ordenar la 


\section{Rafael Arroyo llera \\ Fuentes numismáticas}

colección siguiendo pautas que no venían al caso, pues el dato fundamental era precisamente su origen.

Y por último tenemos que señalar la existencia de colecciones particulares que pueden ser de dos maneras: Colecciones formadas por adquisiciones de hallazgos locales y con indicación de procedencia. Las cuales son interesantísimas y por lo tanto necesitadas de un estudio y publicación aún más urgente que el de los fondos de los Museos, pues existe el peligro de enajenación. Y Colecciones formadas con materiales sin procedencia. En este caso el interés es menor, pero también es conveniente su estudio, pues las marcas, metrología y tipos sólo se pueden estudiar cuando se tienen recogidos un número importante de piezas.

\section{c) Problemas de la descripción del material.}

Es justamente con los anteriores aspectos uno de los más interesantes de la numismática actual y que posiblemente estaría necesitado de una reunión de especialistas a nivel nacional.

El problema surge en el momento de tener que describir un material numismático en una publicación. La falta de uniformidad es completa, cada uno de los numismáticos españo- 


\section{Arqueología del País Valenciano: panorama y perspectivas}

les describe la moneda a su manera sin ajustarse a ningún tipo de normas. Los más avezados en la bibliografía del momento la citarán aproximándose a criterios anglosajones o franceses. Quienes publican monedas no siendo esa su especialidad las formas de descripción pueden ser originalísimas.

Los errores más corrientes en este sentido se pueden resumir en lo siguiente: aquellos investigadores que no conociendo bien las diferencias entre las especies monetarias confunden el as con el dupondio, el denario con el antoniniano, el nummus con el antoniniano de cobre. $Y$ no entramos en las diferencias entre el bronce y el oricalco. Todavía existen publicaciones que siguen hablando de grandes bronces, medianos y pequeños, que es como decirle a un prehistoriador piedras grandes, medianas y pequeñas.

Al lado de esto se encuentran los errores de cronología. Si al describir un sestercio de Trajano colocamos la fecha total de su reinado, es un dato que no sirve para nada, pues lo correcto es situar la cronología de la pieza descrita según la emisión, siempre y cuando se conozca. Lo cual obliga a tener que utilizar referencias bibliográficas modernas.

En donde el confusionismo es más grande y no sólo a nivel nacional sino internacional es en la descripción del anverso 


\section{Rafael Arroyo llera \\ Fuentes numismáticas}

y reverso. Hay publicaciones que las descripciones son exhaustivas hasta el extremo de describir detalles mínimos, alargando innecesariamente la publicación, pues con incorporar una bibliografía internacional es suficiente. De todas las maneras tenemos períodos en la moneda romana que la combinación de bustos, o cabezas, o vestimenta dificulta el uniformar la descripción y en este caso lo mejor es atenerse a fórmulas ya reconocidas por ejemplo las utilizadas en el RIC para Galieno:

a. Busto radiado, con coraza a derecha.

b. Busto radiado con paludamentum, visto de perfil.

c. Busto radiado con coraza, a la derecha, con paludamentum.

d. Busto radiado con coraza a izquierda.

e. Cabeza radiada a derecha.

En este sentido se plasma la lista al principio o en una nota y en la descripción del material no es necesario repetirlo en cada moneda sino sólo la letra que corresponda.

En cuanto a la descripción material de la moneda también se dan toda clase de variantes: quienes sólo colocan el peso y 


\section{Arqueología del País Valenciano: panorama y perspectivas}

a lo sumo el diámetro, y quienes señalan toda clase de datos: peso, diámetro, grosor, posición de cuño y conservación. Hay que pensar que cuantos más datos se ofrezcan mayores posibilidades de estudio tendrá el material presentado.

Toda moneda debe de ir acompañada de su referencia bibliográfica y ésta debe de ser la más reciente o del corpus internacional más conocido, en líneas generales hoy día al tradicional Cohen le ha suplantado el mucho más completo Roman Imperial Coinage, o los estudios monográficos de un emperador como los dedicados por P. Bastien a Postumo y Magnencio.

Recientemente P. Bastien (1981) ha recogido en uno de sus últimos trabajos algunas de las anteriores preocupaciones así como la necesidad de una cooperación internacional para dar a los estudios de numismática romana unos planes de investigación previamente decididos en Coloquios o Mesas internacionales. En este sentido y al referirse a la parte gráfica de las monedas hacía hincapié en la necesidad de que cualquier trabajo de numismática fuera acompañado de la mayoría de las fotos, pues una moneda descrita y fotografiada es un dato analizable y si sólo está descrita cabe pensar que se ha podido introducir un error. Siempre, por tanto, es 


\section{Rafael Arroyo llera \\ Fuentes numismáticas}

preferible reducir las descripciones al mínimo y aumentar la parte gráfica, será un dato que siempre será utilizable.

Una parte que cada vez va teniendo más importancia es la publicación de hallazgos o tesorillos. Los anteriores a 1945 por lo general se tratan de descripciones con muchos fallos y por tanto incompletos. Los publicados en los últimos años están bajo una normativa correcta. Esto ha sido posible gracias a publicaciones de cierta altura como los Coins Hoards (nota 3) ingleses, o los más recientes Trésors Monetaires (nota 4)franceses, juntamente con la excelente publicación belga de Numismatique Romaine, essais, recherches et documents.

\section{Líneas actuales de investigación}

En parte las líneas generales de la investigación numismática en la actualidad siguen las directrices que hemos esbozado al plantear los problemas con que cuenta la numismática romana imperial. Por una parte se está iniciando la publicación de algunos de los materiales numismáticos que se conservan en los organismos oficiales, en particular el Monetario de la Universidad de Valencia, Museo Arqueológico de Sagunto, Alcoy, Alicante y Elx. Aunque en este sentido aún queda mucho por hacer. 


\section{Arqueología del País Valenciano: panorama y perspectivas}

Otra línea segunda en la investigación son algunas publicaciones sobre los materiales procedentes de excavaciones, en este sentido hay que mencionar los primeros resultados del Grau Vell de Sagunt, el yacimiento de Sant Josep (Vall d'Uxó), los materiales no publicados aún del yacimiento tardorromano de Altea, Excavación de Santa Bárbara, La Vilavella (Castellón). En algunas ocasiones las monedas no proceden directamente de excavación pues son hallazgos esporádicos como en "Estudio numismático de la villa de Benicató (Nules, Castellón)”.

De todas maneras los estudios que más auge están teniendo son los relativos a la circulación monetaria. En 1979 se celebró el /l Symposium Numismático de Barcelona que estaba centrado en el tema de la circulación monetaria. Con este motivo se aportaron materiales y cuantificaciones de gran interés. Aunque sus resultados científicos están todavía lejanos para tener un panorama concreto. Las cuantificaciones se realizaban tomando períodos muy largos y con materiales muy diversos. La circulación monetaria no se conocerá hasta que no se realicen trabajos muy monográficos tomando períodos muy cortos, pero de un análisis intenso. En este sentido hemos iniciado varios trabajos: "Las acuñaciones de los emperadores galo-romanos y su circulación mo- 


\section{Rafael Arroyo llera \\ Fuentes numismáticas}

netaria en el País Valenciano" (ARROYO, 1980 a), "limitaciones de la moneda romana del siglo IV en la circulación monetaria valenciana" (ARROYO, 1980 b), "Consideraciones Sobre algunas monedas romanas inéditas de imitación del siglo IV d.C." (ARROYO, 1981), "Vespasiano y su proyección monetaria en tierras valencianas" (ARROYO, 1980 c), "Las acuñaciones de Magnencio y su presencia en las tierras valencianas" (ARROYO, 1980 d) y "Volumen y repercusión de la inflación monetaria romana del 261-269 d.C., en la Tarraconense Costera Meridional” (ARROYO, 1982 b).

En Murcia y Albacete trabajos de circulación de estos períodos recientes no tenemos constancia, pero hay que señalar algunas publicaciones de interés como el "Tesorillo de monedas de Algezares (Murcia)" (BELTRÁN, 1947) y "El tesoro numismático de Riopar (Albacete)" (SÁNCHEZ, 1945).

\section{Directrices para el futuro}

La investigación sobre la numismática romana imperial está en función de las mayores o menores vocaciones que surjan, y se trata de un período que se halla en inferioridad de condiciones frente a una numismática ibérica o ibero-romana, pues la antigüedad por una parte y el aspecto local por otro atraen más fácilmente a los estudiosos. Sin embargo queda 


\section{Arqueología del País Valenciano: \\ panorama y perspectivas}

en el período romano multitud de preguntas y de cuestiones que sólo con un trabajo muy sistemático podrá llegar a conocerse.

En primer lugar hay que hacer un esfuerzo para dar a conocer los fondos numismáticos de los museos publicándolos adecuadamente y con los suficientes datos.

En segundo lugar es necesario dar a conocer todos los materiales numismáticos de las excavaciones, procurando no desechar pieza alguna por estropeada que se encuentre. Aunque nosotros pensamos que el análisis de las monedas, sin dudar de los conocimientos que pueden tener los colegas arqueólogos, deberían de ser estudiados por numismáticos, para que la descripción fuera más adecuada.

En cuanto a los estudios de circulación monetaria deben de dirigirse hacia aquellos aspectos que al hablar de los problemas hemos planteado, aunque todo ello no sea posible si antes no se cuenta con una base material lo suficientemente amplia y numerosa.

Por último se están iniciando proyectos de estudios en colaboración con otras universidades y organismos, en este sentido hay que señalar la creación de un Banco de Datos Numismáticos, proyecto que se halla en manos de $\mathrm{M}$. 


\section{Rafael Arroyo llera \\ Fuentes numismáticas}

Campo del Gabinet Numismàtic de Catalunya, y de T. C. Volk del Fitzwilliam Museum (Cambridge).

Con lo anterior se intenta tener un registro sistemático de los materiales numismáticos a través de ordenadores, tal como cuenta ya el American Numismatic Society de Nueva York. En este banco de datos se incluirían las colecciones de los museos, los hallazgos de tesoros, los hallazgos de yacimientos y los hallazgos sueltos. El trabajo actual está en fase de realizar el tipo de ficha lo suficientemente completo que abarque los temas anteriores y a la vez pueda programarse.

De completarse este proyecto será sin duda la línea de trabajo más moderna en cuanto a disponibilidad de material. Pues un investigador a partir de este momento dispondrá de datos suficientes para elaborar cuantas cuestiones de circulación monetaria le interese.

\section{Bibliografía}

ARANEGUI GASCO, C. 1980: "La circulación monetaria en el Grau Vell de Sagunt (Valencia)", Actas del IV Congreso Nacional de Numismática, 59 ss. 


\section{Arqueología del País Valenciano: panorama y perspectivas}

ARROYO ILERA, R. 1980 a: "Las acuñaciones de los emperadores galo-romanos y su circulación en el País Valenciano", I/ Simposi Numismatic de Barcelona, 31 ss.

- 1980 b: "Imitaciones de la moneda romana del siglo IV en la circulación monetaria valenciana", Numisma 165-167.

- 1980 c: "Vespasiano y su proyección monetaria en tierras valencianas", Saguntum, 15, 191-206.

- 1980 d: "Las acuñaciones de Magnencio y su presencia en tierras valencianas", Acta Numismática, X.

- 1981: "Consideraciones sobre algunas monedas romanas inéditas de imitación del siglo IV d.C.", Saguntum, 16, 271-274.

- 1982 a: "Volumen y repercusión de la inflación monetaria romana del 261-269 d.C. en la Tarraconense Costera Meridional", Saguntum, 17, 131-145.

- 1984: El Numerario de la Universidad de Valencia, catálogo, estudio e interpretación de las monedas de la Edad Antigua. Valencia.

BABELÓN, E. 1901-1904: Traité des monnaies grecques et romaines. Paris. 
BANTI-SIMONETTI: Corpus Nummorum Romanorum. 18 vol.

BASTIEN, P. 1964: Le monnayage de Magnence (350-53). Wetteren.

- 1967: Le monnayage de bronze de Postume. Wetteren.

- 1981: "Numismatique romaine et cooperation international", Numismatique Romaine, essais, recherches et documents, 126 ss.

BASTIEN, P. et HUVELIN, H. 1969: Trouvaille de folles de la periode Constantienne (307-317). Wetteren.

BELTRÁN, A. 1947: "El tesorillo de monedas de Algezares (Murcia)", Crónica del III Congreso Arqueológico del Sudeste (Cartagena).

BRUUN, P. 1966: The Roman Imperial Coinage. Vol. VII. Constantine and Licinius. London.

CAMPO, M. 1974: "Los problemas de imitación de Claudio I en Hispania", Acta Numismática, IV, 155-163.

CARANDINI, A. 1969-70: "Produzione agricola e produzione ceramica nell'Africa de etá imperiale", Studi Miscellanei, 15. 


\section{Arqueología del País Valenciano: panorama y perspectivas}

CAVALLER, J.V. 1980: "Conjunt monetari tardo-roma procedent del jaciment de Sant Josep (La Vall d'Uxó)", Cuadernos de Prehistoria y Arqueología Castellonense, 7.

COHEN, H. 1880: Description historique des monnaies frappés sous l'empire romain jusqu'a la chute de l'empire d'Occident. Paris.

DEPEYROT, G. 1979: "L'organisation de la frappe dans l'atelier monetaire d'Arles au IVème siècle", Actes du 9ème Congrès International de Numismatique (Berne), 544 ss.

- 1982: Le numéraire gaulois du IVe siècle. London.

DOÑATE SEBASTIA, J.M. 1969: "Arqueología romana de Villarreal”, Archivo de Prehistoria Levantina, XII.

ESCRIG NÚÑEZ, E. 1966: "Numismática saguntina”. Arse, 8.

GIARD, J.B. 1970: "Pouvoire central et libertés locales. Le monnayage en bronze de Claude avant 50 après J.C.", Revue Numismatique, XII, 39-40.

GINER BOLUFER, C. 1947: "La arqueología de Pego y su comarca", Actas del I Congreso Arqueológico del Levante Español; Saitabi, V, 23-24. 


\section{Rafael Arroyo llera \\ Fuentes numismáticas}

KENT, J.P.C. 1981: The Roman Imperial Coinage. Vol. VIII. The family of Constantine I A.D. 337-364. London.

LAFFRANCHI, L. 1949: "La monetazione imperatoria e senatoria di Claudio I durante II quadriennio 41-44 d.C.", Rivista Italiana di Numismatica LL

MANGAS, J. 1971: "Un capítulo de los gastos en el municipio romano de Hispania a través de las informaciones de la epigrafía latina", Hispania Antiqua, 1, 105 SS.

MATTINGLY, H.: Coins of the Roman Empire in the British Museum. London.

- 1923: Vol. I. Augusto-Vitelio.

- 1930: Vol. II. Vespasiano a Domiciano.

- 1936: Vol. III. Nerva a Adriano.

- 1940: Vol. IV. Antonino Pío a Commodo.

- 1950: Vol. V. Pertinax a Eliogabalo.

- 1950: Vol. VI. Severo Alejandro a Balbino y Pupieno.

MATTINGLY, H. y SYDENHAM, E. 1923: The Roman Imperial Coinage. Vol. I. London. 


\section{Arqueología del País Valenciano: panorama y perspectivas}

- 1926: The Roman Imperial Coinage. Vol. II. Vespasian to Hadrian. London.

MATTINGLY, H.. SYDENHAM, E. y SUTHERLAND, C. V. 1938: The Roman Imperial Coinage. Vol. IV, part II. Macrinus to Pupienus. London.

MULLER, L. 1860: Numismatique de l'ancienne Afrique, ouvrage avec C.T. Falbe et J.Ch. Lindberg. Copenhague.

PANELLA, C. 1972: "Stratigrafie delle terme ostiensi del Nuotatore", Recherches sur les amphores romaines. Roma.

PEARCE, J.W.E. 1933: The Roman Imperial Coinage. Vol. IX. Valentinian I to Theodosius I. London.

PIGANIOL, A. 1965: Les empereurs romains d'Espagne. Paris.

RIPOLLÉS ALEGRE, P.P. 1975: "Hallazgos numismáticos en Albocácer, Cabanes y Borriol", Cuadernos de Prehistoria y Arqueología Castellonense, 2.

- 1978: "Los hallazgos numismáticos de la excavación de Sant Josep, Vall d'Uxó", Cuadernos de Prehistoria y Arqueología Castellonense, 5. 
RAMOS FERNÁNDEZ, R. 1975: La ciudad romana de Illici. Estudio arqueológico. Alicante.

SABATIER, I. e L. 1850: Production de l'or, l'argent et du cuivre chez les ancien et hôtels monetaires des empires romain et bizantin. San Petersburgo.

SÁNCHEZ JIMÉNEZ, J. 1945: "El tesoro numismático de Riopar (Albacete)", Memorias de los Museos Arqueológicos Provinciales. Albacete.

- 1951: "Inventario de los hallazgos monetarios en la provincia de Albacete", Anales del Seminario de Historia y Arqueología de Albacete.

- 1962: Descripción de hallazgos en Publicaciones del Seminario de Historia y Arqueología de Albacete.

SANTANDREU, M.C. 1961: "Hallazgos en el cauce del Turia", Archivo de Prehistoria Levantina,IX.

SUTHERLAND, C. H. V. 1935: Romans British imitations of bronze coins of Claudius I. New York.

- 1973: The Roman Imperial Coinage. Vol. VI. From Diocletian's reform (ad. 294) to the death of Maximinus (A.D. 313). London. 
Arqueología del País Valenciano:

panorama y perspectivas

- 1974: Monnaies romaines. Fribourg.

VERA ALEXANDRE, M.: Hallazgos numismáticos en 1967, 1969. 1972-73, 1975-76 y 1977 todos ellos publicados sucesivamente en Arse.

WEBB, P. 1927: The Roman Imperial Coinage. Vol. V. part I. London. 
1 Se comienza con Pompeyo y Marco Antonio y termina en el volumen 18 con las monedas de bronce de Nerón.

2 Aspectos más amplios de este problema se pueden ver en G. Depeyrot (1982).

3 En 1975 se comenzó a publicar los Coins Hoards por la Royal Numismatic Society hasta la fecha de hoy llevan dados a conocer VI volúmenes, abarcando tanto los hallazgos griegos como los romanos y los celtas y bizantinos.

4 Bajo la dirección de J.B. Giard y publicado por el departamento de monedas de la Bibliotheque National de Paris se inició en 1979 los Tresors Monétaires, hasta la actualidad publicados IV volúmenes. 